Short Communication

\title{
EFFECT OF HEATING TIME AND HEAT ON THE PHYSICOCHEMICAL AND ANTIOXIDATIVE PROPERTY OF FISH (LABEO ROHITA) SKIN OIL
}

\author{
NABANITA GHOSH ${ }^{*}$, DIPAK KUMAR BHATTACHARYYA ${ }^{2}$
}

${ }^{1,2}$ School of Community Science and Technology, Indian Institute of Engineering Science and Technology Shibpur, Howrah, India Email: naba1990@gmail.com

Received: 03 Mar 2019 Revised and Accepted: 25 Jul 2019

\begin{abstract}
Objective: Determination of oxidative and thermal stability of Labeo rohita skin oil.

Methods: Labeo rohita skin oil was extracted by soxhlet method using n-hexane as solvent. Acid value, Free Fatty Acid content, the Peroxide value of the oil was determined and the same was also determined after heating the oil at $90^{\circ} \mathrm{C}$ for 1 hour to check whether the oil is thermally stable or not. Antioxidant activity was determined via Total Phenolic content (TPC), 2, 2-Diphenyl-1-picryl hydrazyl (DPPH) free radical scavenging activity and Ferric Reducing Antioxidant Power (FRAP) assay. Oxidative stability was determined by heating the oil at a constant temperature of $90{ }^{\circ} \mathrm{C}$ for 1
\end{abstract} hour, 2 hour, 3 hour, and 4 hour. The oil was also heated at $60^{\circ} \mathrm{C}, 120^{\circ} \mathrm{C}$, and $18{ }^{\circ} \mathrm{c}$ for a constant time of $2 \mathrm{~h}$.

Results: Heating increases the scavenging activity of Labeo rohita skin oil as measured by the 2, 2-Diphenyl-1-picryl hydrazyl (DPPH) method. Total phenolic content (TPC) value and Ferric reducing antioxidant power (FRAP) assay value is decreased both with an increase in heating time $\left({ }^{* *} \mathrm{p}<0.05\right)$ and heating temperature $(\mathrm{p}<0.01)$. Acid value and FFA (Free Fatty Acid) content and Peroxide value is increased with an increase in temperature $\left({ }^{* *} \mathrm{p}<0.01\right)$

Conclusion: The Present study explores that Labeo rohita skin oil is both thermally and oxidatively stable the results indicate that the oil can be used in food formulation as well as a new cooking oil substitute.

Keywords: Fish Skin Oil, Temperature, DPPH, TPC, FRAP, Acid Value, Peroxide Value

(C) 2019 The Authors. Published by Innovare Academic Sciences Pvt Ltd. This is an open access article under the CC BY license (http://creativecommons.org/licenses/by/4.0/) DOI: http://dx.doi.org/10.22159/ijpps.2019v11i9.32917

Fish skin Oil (FSO) is a by product extracted from discarded fish skin of Labeo rohita. Generally, fish contains $2-30 \%$ fat, and about $50 \%$ of the body weight is generated as waste during the fish processing operationin the form of skins, scales, bones, viscera, gills, dark muscles and heads [1]. Fish are rich in essential fatty acids mainly Eicosapentanoic Acid (EPA), among which the long chain unsaturated fatty acids $\left(\mathrm{C}_{20}\right.$ and $\left.\mathrm{C}_{22}\right)$ are of great importance forthe human body [2].

Lipid oxidation is a particular problem in foods enriched with n-3 polyunsaturated fatty acids. Oxidation of lipids produces rancid odors and flavors and also decreases nutritional quality and safety by the formation of secondary products [3]. Antioxidants are substances used to prevent deteriorative changes in oils due to oxidation. The antioxidative property of oil can be measured quantitatively using 2, 2-Diphenyl-1-picryl hydrazyl (DPPH) free radical scavenging activity, Total Phenolic content (TPC) test, Ferric Reducing Antioxidant Power (FRAP) assay.

Temperature is one of the most important factors that affect the antioxidative property as well as physicochemical properties. Oils undergo heat treatment during their processing and cooking and due to heating oil at high-temperaturehydroperoxides are formed that can cause various health problems [4].

Application of heat causes organoleptic deterioration of oils and makes it unsuitable for use. The aim of the present study is to evaluate that whether fish skin oil (FSO) can withstand the stress of heat application and to determine the heating effect on quality and stability of fish skin oil (FSO). The present study reveals the changes in antioxidative and physicochemical properties of fish skin oil (FSO) with increase in heating time and temperature.

Fish skin was collected from a local market of Serampore town, Hooghly, West Bengal, India. The skin was then washed and the scales were separated from skin properly. The washed skins were kept in an airtight container and stored at- $20{ }^{\circ} \mathrm{C}$ until further use. Before oil extraction, the skin was thawed to room temperature.
Stored fish skin samples were dried at $60{ }^{\circ} \mathrm{C}$ for $24 \mathrm{~h}$ in a hot air oven under vacuum the dried samples, after grinding in a morter with a pestle soaked in food grade $n$-hexane in $1: 10(\mathrm{w} / \mathrm{v})$ ratio. The oil is extracted using soxhlet apparatus according to the Association of Official Analytical Chemists (AOAC) 1990 method [5], followed by filtration and distillation of the solvent in a water evaporator. The oil collected is stored at $4{ }^{\circ} \mathrm{C}$ for further analysis.

The total amount of oil extracted was determined and calculated by using equation 1 .

$$
\text { Percentage of yield }=\frac{\mathrm{w} 2-\mathrm{w} 1}{\mathrm{w} 3} \times 100 \ldots
$$

Where W1= weight of flask alone in kilogram, W2= weight of flask and oil in kilogram, $\mathrm{W} 3=$ weight of the dried fish skin sample used for oil extraction in kilogram.

The oil was subjected to physicochemical analysis via Acid value, Free Fatty acid content and Peroxide value. Acid value was determined according to American Oil Chemists' Society (AOCS) ca $5 a-40$ (8) method by taking $0.001 \mathrm{~kg}$ oil in a conical flask, to these 3 drops phenolphthalein was added, followed by addition of $20 \mathrm{ml}$ ethanol. The mixture was titrated with $0.1(\mathrm{~N}) \mathrm{NaOH}$ solutions until a pink color developed. This value was calculated by the equation 2 .

$$
\text { Acid value }=\frac{56.1 \times \mathrm{N} \times \mathrm{V}}{\mathrm{W}}
$$

Where $\mathrm{N}=$ Normality of the titration solution, $\mathrm{W}=$ weight of the oil material, $\mathrm{V}=$ Volume of the titrated solution, 56.1 = constant

Free Fatty Acid was determined via American Oil Chemists' Society (AOCS) ca 5a-406 (8) method by weighing $0.001 \mathrm{~kg}$ oil was taken into a conical flask. 3 drops of phenolphthalein indicator and $20 \mathrm{ml}$ ethanol was added to the oil the mixture was titrated with $0.1 \mathrm{M} \mathrm{NaOH}$ solution until a pink color developed. Free fatty acid was calculated by equation 3 .

$$
\text { Free fatty acid }=\frac{\mathrm{V} \times \mathrm{N} \times 28.2}{\mathrm{~W}} \ldots \ldots . . .(3)
$$


Where $\mathrm{V}=$ Volume of the titration solution, $\mathrm{N}=$ Normality of the titrated solution, $\mathrm{W}=$ weight of oil, 28.2 = constant.

Peroxide value had been determined according to the Association of Official Analytical Chemists (AOAC) 965.33 (8). $0.001 \mathrm{~kg}$ of oil sample was weighed. $0.001 \mathrm{~kg}$ of powdered potassium iodide (KI) and $20 \mathrm{ml}$ of a solvent mixture $(2$ volume glacial acetic acid +1 volume chloroform) was added to the oil and heated in a water bath. The content titrated with 0.002 Mole sodium thiosulphate solution using starch as the indicator. This value was calculated using the following formula given in equation 4 .

$$
\text { Peroxide value }=\frac{(\mathrm{V} 1-\mathrm{V} 0) \times \mathrm{C} \times 1000 \times \mathrm{T}}{\mathrm{W}} .
$$

Where V1= Consumption of 0.01 mol sodium thiosulphate in the main test, $\mathrm{V} 0=$ consumption of $0.01 \mathrm{~mol}$ sodium thiosulphate in blank test, $\mathrm{C}=$ Molarity of sodium thiosulphate, $\mathrm{T}=$ Titrate value of sodium thiosulphate, $\mathrm{W}=$ weight of the oil taken.

Antioxidative property was determined via Total Phenolic Content,2, 2-Diphenyl-1-picryl hydrazyl (DPPH) free Radical Scavenging activity and Ferric Reducing Antioxidant Power(FRAP) activity.

The total phenol content (TPC) was measured using the FolinCiocalteu assay [6]. $0.2 \mathrm{ml}$ of the oil was taken into test tubes followed by $0.5 \mathrm{ml}$ Folin-Ciocalteu's reagent (diluted 10 times with water). The solution was then kept at dark for $5 \mathrm{~min}$ and then $1 \mathrm{ml}$ sodium carbonate $(7.5 \% \mathrm{w} / \mathrm{v})$ was added. The tubes were kept in the dark for 1 hour. Absorption at $765 \mathrm{~nm}$ was measured with a spectrophotometer (Jasco V-630) and compared to a gallic acid calibration curve. The total phenolic content was calculated as gallic acid equivalent (GAE)/gm of sample [7].

2, 2-Diphenyl-1-picryl hydrazyl (DPPH) free Radical Scavenging activity experiment were carried out according to the method of Blois [8] with a modification. A volume of $2 \mathrm{ml}$ of a methanolic solution of the oil was put into test tubes and $2 \mathrm{ml}$ of $1 \mathrm{mmol} \mathrm{2,2-}$ Diphenyl-1-picryl hydrazyl (DPPH) solution was added. The tubes were kept in the dark for 1 hour. Absorbance at $517 \mathrm{~nm}$ was measured with a spectrophotometer (Jasco V-630) and compared to an ascorbic acid calibration curve. The results were expressed as $\mathrm{mg}$ ascorbic acid/g of sample. The percentage inhibition of the 2, 2Diphenyl-1-picryl hydrazyl (DPPH) radical was calculated utilizing the following formula as provided in equation 5 .

$$
\mathrm{I} \%=\frac{\mathrm{A} 0-\mathrm{A}}{\mathrm{A} 0} \times 100 \ldots \ldots(5)
$$

Where I = 2, 2-Diphenyl-1-picryl hydrazyl (DPPH) inhibition, $\mathrm{A}_{0}=$ absorbance of control sample and $A=$ absorbance of tested sample.

The antioxidant activity by Ferric Reducing Antioxidant Power (FRAP) assay was carried out by the method of the ferric reducing ability of plasma (FRAP) assay of Benzie and Strain (1996) [9] with slight modifications. To $20 \mu \mathrm{L}$ of sample and $180 \mu \mathrm{L}$ of Ferric Reducing Antioxidant Power (FRAP) reagent was added and incubated at $37^{\circ} \mathrm{C}$ for 40 minute in the dark. The absorbance of the resulting solution was measured at $593 \mathrm{~nm}$ in a UV spectrophotometer (Jasco V-630). The change in absorbance between the final reading (4-minute reading) and blank reading $(0$ minute reading) of the sample and the same of standard Ascorbic acid was selected for the calculation of Ferric Reducing Antioxidant Power (FRAP) value which is calculated by utilizing the formula as shown in equation 6.

FRAP value $=\frac{\text { sample changes from } 0 \mathrm{~min} \text { to } 4 \mathrm{~min}}{\text { standard changes from } 0 \mathrm{~min} \text { to } 4 \mathrm{~min}} \times$ FRAP value of standard ......... (6)

To evaluate the changes that occurs during the heating of an oil, fish skin oil sample were heated for $1 \mathrm{~h}, 2 \mathrm{~h}, 3 \mathrm{~h}$ and $4 \mathrm{~h}$ at a constant temperature of $90^{\circ} \mathrm{C}$ separately and for a constant time of $2 \mathrm{~h}$ at $60^{\circ} \mathrm{C}$, $120^{\circ} \mathrm{C}$ and $180^{\circ} \mathrm{C}$ temperature and the changes in physicochemical and antioxidative properties were compared with an unheated control. All tests were performed in triplets and data is presented as mean \pm Sstandard deviation (SD). Statistical significance was performed using ANOVA one way Tukey Test.

\begin{tabular}{|c|c|c|c|c|c|}
\hline Test & Control & $1 \mathrm{~h}$ heated & 2 h heated & $3 \mathrm{~h}$ heated & $4 \mathrm{~h}$ heated \\
\hline DPPH & $3.84 \pm 0.02$ & $12.18 \pm 0.07^{a}$ & $24.52 \pm 0.11^{\mathrm{b}}$ & $37.57 \pm 0.09^{c}$ & $75.76 \pm 0.09^{d}$ \\
\hline TPC & $6.50 \pm 0.02$ & $5.73 \pm 0.16^{a}$ & $3.39 \pm 0.08^{b}$ & $2.11 \pm 0.07^{c}$ & $1.05 \pm 0.03^{\mathrm{d}}$ \\
\hline FRAP & $990 \pm 1.52$ & $52 \pm 0.09^{a}$ & $44.33 \pm 1.33^{\mathrm{a}}$ & $32 \pm 0.05^{\mathrm{a}}$ & $10.36 \pm 1.49^{b}$ \\
\hline
\end{tabular}

Table 1: Changes in antioxidative property with variation in heating time at a constant temperature of $90{ }^{\circ} \mathrm{C}$

All tests are performed in triplets. Data is expressed as mean \pm SD. Different letters in the same row represent significant differences $p<0.01$.

Table 2: Changes in antioxidative property with temperature variation at a constant time of $2 \mathrm{~h}$

\begin{tabular}{lllll}
\hline Test & Control & $\mathbf{6 0}^{\circ} \mathbf{c}$ & $\mathbf{1 2 0}^{\circ} \mathbf{c}$ & $\mathbf{1 8 0}^{\circ} \mathbf{c}$ \\
\hline DPPH & $3.84 \pm 0.02$ & $8.74 \pm 0.16^{\mathrm{a}}$ & $15.26 \pm 0.09^{\mathrm{a}}$ & $30.34 \pm 0.12^{\mathrm{a}}$ \\
TPC & $6.50 \pm 0.02$ & $6.23 \pm 0.06^{\mathrm{a}}$ & $4.24 \pm 0.05^{\mathrm{a}}$ & $1.84 \pm 0.03^{\mathrm{c}}$ \\
FRAP & $990 \pm 1.52$ & $57.33 \pm 0.06^{\mathrm{a}}$ & $35 \pm 0.06^{\mathrm{b}}$ & $11.33 \pm 0.04^{\mathrm{a}}$ \\
\hline
\end{tabular}

All tests are performed in triplets. Data is expressed as mean \pm SD. Different letters in the same row represent significant differences $p<0.05$.

Table 3: Changes in physicochemical property with heating at $90^{\circ} \mathrm{c}$ for $1 \mathrm{~h}$

\begin{tabular}{lll}
\hline Indices & Control & 1 hour heated \\
\hline Acid Value (AV) & $3.36 \pm 0.20$ & $3.70 \pm 0.02^{\mathrm{a}}$ \\
Free Fatty Acid (FFA) & $1.69 \pm 0.03$ & $2.12 \pm 0.06^{\mathrm{b}}$ \\
Peroxide Value (PV) & $5.75 \pm 0.10$ & $7.45 \pm 0.01^{\mathrm{c}}$ \\
\hline
\end{tabular}

All tests are performed in triplets. Data is expressed as mean \pm SD. Different letters in the same column represent statistical significance $\mathrm{p}<0.01$

Results reveals that the oil yield from Labeo rohita skin was $23.20 \%$, which is of good quantity. The antioxidant activity is determined to check whether the oil can be stable both thermally and oxidative during cooking. The antioxidative activity was examined via 2, 2Diphenyl-1-picryl hydrazyl (DPPH) free radical scavenging activity, Total Phenolic Content (TPC), and Ferric reducing ability of plasma (FRAP) assay at different temperature of $60^{\circ} \mathrm{C}, 120^{\circ} \mathrm{C}, 180^{\circ} \mathrm{C}$ with a constant heating time of $2 \mathrm{~h}$ and at $90^{\circ} \mathrm{C}$ with a variation in heating time of $1,2,3$ and $4 \mathrm{~h}$. As shown in table 1 and table 2 . From the above-mentionedtable, it is observed that heating increases the scavenging activity of fish skin oil (FSO) as measured by the 2, 2Diphenyl-1-picryl hydrazyl (DPPH) method and it matches with previous works [10]. Total Phenolic Content (TPC) value and ferric reducing ability of plasma (FRAP) value is decreased both with an 
increase in heating time $(\mathrm{p}<0.05)$ and heating temperature $(\mathrm{p}<0.01)$, which is also similar to the previously established work [11].

Significant changes are also observed in the physicochemical properties of fish skin oil (FSO). To determine whether fish skin oil (FSO) can withstand against high temperature, it is heated for 1hour at $90{ }^{\circ} \mathrm{C}$ and the Acid value, Peroxide value and free fatty acid content of the heated oil was measured. Peroxide value is increased with an increase in temperature. Such an increase in peroxide value (PV) with temperature was also reported by Jeorge (1997) [12] and Maduelosi (2015) [13] and it indicates the formation of hydroperoxides that deteriorates the oil [13]. Hydroperoxides are formed as a result of lipid oxidation [14]. Acid value and free fatty acid (FFA) content is also increased with an increase in temperature and it is likely to matches previously performed work [15].

On the basis of the tests that are performed, this study explores that fish skin oil (FSO) has both thermal and oxidative stability against increase temperature. The results also indicates that fish skin oil (FSO) can be taken into account for its use in food formulation as well as a new cooking oil substitute due to its physicochemical as well as antioxidative stability against increased temperature.

\section{ACKNOWLEDGMENT}

The authors are grateful to Indian Institute of Engineering Science and Technology (IIEST) Shibpur, Howrah, India for providing the scope to perform all significant tests in the laboratory of the School of Community Science and Technology (SOCSAT). The authors are also thankful to the School of Community Science and Technology, (SOCSAT), Indian Institute of Engineering Science and Technology, Shibpur for providing financial support.

\section{AUTHOURS CONTRIBUTIONS}

All tests have been performed diligently by the authors and both the authors equally contributed to the work. The first author is the research fellow of the work and the second author is the principal investigator (PI).

\section{CONFLICT OF INTERESTS}

Both the author declares that there is no conflict of interest

\section{REFERENCES}

1. F Guerard, L Guimas, A Binet. Production of tuna waste hydrolysates by a commertial neutral protease preparation. J Mol Catal B Enzym 2002;19:489-98.
2. J Sergent, G Bell, L McEvoy, D Tocher, A Estevez. Recent developments in the essential fatty acid nutrition of fish. Aquaculture 1999;177:191-9.

3. Zuzana REBLOVA. Effect of temperature on the antioxidant activity of phenolic acids. Czech J Food Sci 2012;30:171-7.

4. Alavi L, Barzegar M, Jabbari A, Naghdi Badi H. Effect of heat treatment on chemical composition and antioxidative property of Thymus daenensis essential oil. J Med Plants 2010;9:129-38.

5. AOAC. Official methods of analysis. $15^{\text {th }}$ edition. Association of Official Analytical Chemists, Arlington, VA, USA; 1990.

6. KR Athira, TV Binu. Market sample survey of Crocus sativus linn. to asses the genunity for using antioxidant activity, total phenolic content and high-pressure thin layer chromatography using detection of flavonoids. Int J Curr Pharm Res 2019;11:30-3.

7. Ruwali P, M Adhikari, S Sharma. Phytochemical and antioxidant properties of various extracts of Michelia champaca leaves. Int J Pharm Pharm Sci 2019;11:56-61.

8. Vidya Kamble, Nikhil Gaikward. Fluorescence analysis, phytochemical and antioxidant activity in leaves and stem of Embelia ribes burm. F. Asian J Pharm Clin Res 2019;12:225-9.

9. Benzie IF. The ferric reducing ability of plasma (FRAP) as a measure of "Antioxidant power": The FRAP assay. Anal Biochem 1996;239:70-6.

10. Tomaino A, Cimino F, Zimbalatti V, Venuti V, Sulfaro V, De Pasquale A, et al. Influence of heating on antioxidant activity and the chemical composition of some spices, essential oils. Food Chem 2005;89:549-54.

11. Indira Priyadarsini K, Dilip KM, Naik GH, Sudheer Kumar M, Unni Krishnan MK, Satav JG, et al. Role of phenoilc O-H and methylene hydrogen on free radical reaction and antioxidant activity of curcumin. Free Rad Biol Med 2003;35:475-84.

12. Jeorge. Natural antioxidants for preventing colour loss in stored Paprika. J Food Sci 1997. p. 65. https://doi.org/10.1111/j.1365-2621.1997.tb15027.x

13. Donelli JK, Robinson DS. Free radicals in foods. Free Rad Res 1995;22:147-76.

14. Angaye SS, Maduelosi NJ, Amadi C. Effect of heat on the physiochemical properties of groundnut oil. Int J Sci Res 2015;4:1278-80.

15. SS Angaye, GK Fekarurhobo, NJ Maduelosi. Comparative study of the oxidative stabilities of plam oil and olive oil. J Nat Sci Res 2013;3:18-28

16. Emhemmed A, Alhibshi Jalal, A Ibrahim, Abdulgadir S Hadad. Effect of heat processing and storage on characteristics and stability of edible oils. $6^{\text {th }}$ Int Conference on Agriculture Environment and Biological Sciences (ICAEBS'16) Dec. 21-22, Kuala Lumpur (Malaysia); 2016. p. 105-9. 